\title{
LA FRONTERA QUE NOS UNE: PROYECTO PARA EDUCAR AL BÁRBARO, MÉXICO, 1807
}

\author{
Laura Hillock
}

RESUMEN: Fuertemente influenciado por las ideas ilustradas que circulaban por las colonias hispanoamericanas a fines del siglo XVIII, y por el contacto con misioneros europeos procedentes de Asia, un hermano franciscano elaboró un proyecto para establecer un colegio de misiones dónde educar al indio bárbaro de las Provincias Internas de la Nueva España. En ese mismo colegio habría cabida para niños provenientes de la China y de otras naciones asiáticas.

El artículo revisa los planteamientos del religioso que justificaban su ambicioso proyecto, y los antecedentes socio-históricos que lo respaldaron. Uno de los ángulos fundamentales se centró sobre el contacto entre las distintas culturas y los beneficios que se obtendrían por el mismo.

Con la invasión napoleónica de España y los movimientos independentistas de las colonias españolas, la realización del proyecto peligró, pero la iniciativa fue reflejo de una necesidad real de educar y civilizar al bárbaro.

Palabras clave: Nueva España, frontera, proyecto educativo, misiones, franciscanos.

ABSTRACT: Strongly influenced by the enlightened ideas that were making their rounds throughout the Spanish American colonies toward the end of the 18th Century, and due to the contact with European missionaries from Asia, a Franciscan friar took it upon himself to design a project for a Mission School for Indian children from the Internal Provinces of New Spain. The same school was to provide education for children from China and other Asian nations.

This article revises the reasons that sustained the friar's ambitious project, and the social and historical background that justified it. One of its principal aspects centered on the contact between the different cultures and the benefits that would be obtained by it.

The invasion of Spain by Napoleon and the colonial efforts to gain independence from the mother country endangered the project, but the initiative was a reflection of a real need to educate and civilize the Barbarian.

Keywords: New Spain, borderbands, educational project, missions, franciscans. 


\section{Introducción}

La frontera norte del virreinato de la Nueva España consistía en un territorio de enormes dimensiones que representaba serias dificultades para la sociedad colonial de la segunda mitad del siglo XVIII. La preocupación por los varios aspectos que la conformaron, entre ellos, sus habitantes, en especial al que se acostumbraba llamar bárbaro, se reflejó en distintos escritos, proyectos e iniciativas gubernamentales y particulares.

En 1774, Don Pedro Alonso $\mathrm{O}^{\prime}$ Crouley $^{1}$ describió gran parte de los territorios de la Nueva España que había conocido durante sus viajes como comerciante. Nacido en Cádiz de padres irlandeses, fue miembro de varias sociedades reales relacionadas con el estudio y el avance de la ciencia, el arte, la agricultura, la industria y el comercio. Mientras se dedicaba a las actividades propias de su profesión, tuvo el tiempo y el interés de acumular un gran número de piezas geológicas y de antigüedades que luego pasaron a formar parte de su valiosa colección privada. También, y gracias a su observación de las diferencias entre los mundos europeo y americano, pudo referirse por escrito a la sociedad colonial y a su pasado prehispánico, a algunas de sus costumbres y tradiciones, a sus ciudades y puertos, a la flora y a la fauna, a los presidios y a la composición racial de la población.

Sus viajes a las colonias coincidieron con los gigantescos esfuerzos de la Corona y del Visitador General Don José de Gálvez quienes, a partir de 1765, se preocuparon de reorganizar administrativamente las enormes extensiones comprendidas por las Provincias Internas del virreinato novohispano. En sus escritos, O’Crouley retrató la situación que se vivía por esos días en la frontera septentrional, comprendida por regiones muy extensas y poco pobladas debido principalmente a su naturaleza agreste, a las grandes distancias involucradas y a los continuos ataques de las tribus bárbaras provenientes de los territorios del norte y que impedían su colonización. Para ello, recurrió a observaciones de primera mano, y a fuentes y documentos históricos a los que tuvo acceso.

El libro de $\mathrm{O}^{\prime}$ Crouley es solo un ejemplo de muchas otras obras e informes escritos por funcionarios, cronistas y viajeros que ofrecían al público europeo una visión del mundo americano. En este caso se trataba de describir variados aspectos del paisaje colonial, entre ellos aquellos vastos territorios al norte del virreinato, mismos que ofrecían un reto enorme a los gobernantes y a los funcionarios borbones. Antes y después de su tiempo se llevaron a cabo varios intentos por colonizarlos, con distintos fines como fueron expandir los territorios y consolidar las posesiones de la Corona, pacificar la enorme zona fronteriza, establecer cordones de protección por medio de la instalación de la cuña presidio-misión, y por

1. O'Crouley, Pedro Alonso, (1774) A Description of The Kingdom of New Spain. Trans. \& edited by Sean Galvin. San Francisco, John Howell Books, 1972. El manuscrito original se encuentra en la Biblioteca Nacional de Madrid. 
ese medio también ofrecer protección a los centros mineros de rica veta y reciente descubrimiento, dejando abierta la posibilidad de nuevos asentamientos humanos a sus alrededores. Otro aspecto fundamental que se quería lograr con una frontera más fortalecida era detener el avance de los franceses por el lado oriental y de incursiones inglesas y hasta rusas por la costa del Pacífico.

La obra a la que hacemos referencia fue también un ejemplo de la mirada ilustrada sobre la situación del indígena, algo que se fue propagando más y más a medida que las ideas circulaban en ambos lados del océano. Si bien el esfuerzo de $\mathrm{O}^{\prime}$ Crouley se centró principalmente en la descripción de los distintos pueblos, de sus vicisitudes y rasgos característicos, también se distingue en él un esfuerzo por entender, por interpretar, la idiosincrasia de la población novohispana.

Entre las bellas ilustraciones que forman parte del texto, se encuentran tres que hacen alusión a los indígenas que habitaban la Nueva España. La primera de ellas describe a los Yndios Caziques, con coloridos trajes a la usanza española. La segunda se refiere a los Yndios mas comunes, con utensilios de labranza en la mano, sin calzado, y con pesados fardos sobre la espalda. El tercero describe a los Yndios Bárbaros con escasa vestimenta y el torso desnudo: el hombre con penacho de plumas y arco y flechas, la mujer cargando a un niño en la espalda, ambos con semblante apacible, lejano de la imagen burda y violenta con la que se les asociaba. Desconocemos si O'Crouley fue el autor de las ilustraciones, pero posiblemente reflejó el imaginario europeo que se tenía de ellos. Recogió en ellas, por un lado, las ideas que evocaban la imagen del noble salvaje del siglo XVIII; por otro, los testimonios de oficiales y de misioneros que tenían contacto más directo con ellos y que los describieron en sus informes.

En su Crónica de mediados de siglo, el Padre Espinosa, y refiriéndose a las misiones al norte de México en manos de los franciscanos, describió algunas de esas tribus que se encontraban enemistadas entre sí, compitiendo por recursos y por espacio. A otros los describió como pacíficos a pesar de lo poco que se había avanzado en el aspecto misional, debido a la inconstancia de los indígenas en adoptar las nuevas costumbres asociadas con el vivir civilizado.

"La provincia de los assinaís, vulgo Texas, se halla en distancia de más de quinientas leguas de la ciudad imperial de México, por el camino que han frecuentado hasta ahora nuestros españoles.... se extiende hasta las orillas del río Missuri.... Es toda esta gente placentera, alegre, de buenas facciones por lo común y muy amigable con los españoles....en tiempo (de caza) van los indios bien armados, porque en esse tiempo, si se encuentran con los apaches, se matan inhumanamente unos a otros"

2. Espinosa, Félix Isidro (1746), Crónica de los Colegios Apostólicos de Propaganda Fide en la Nueva España. Luis Gómez Canedo, ed. Washington, Academy of American Franciscan History, 1964, pp. 689-692. 
La condición del indígena, sobre todo de los que se encontraban más alejados del medio urbano españolizado, seguía preocupando a muchos. Reflejando las iniciativas originadas en España para educar al pueblo, las autoridades civiles y eclesiásticas fueron tomando medidas para remediarla, incluyéndolos en los planes para educar a la totalidad de la población. De esa forma se pretendía sacarlos de la condición de ignorancia y de pobreza en la que se encontraban sumidos, para procurar su inserción en la sociedad colonial.

Varias décadas después de la publicación del libro de O'Crouley, el Padre Mariano López y Pimentel, sacerdote franciscano avecindado en México, se dedicaría con energía y mucho esfuerzo a dar forma a un proyecto para educar a los niños que provenían precisamente de esas tribus llamadas bárbaras: los apaches, comanches, chichimecas, lipanes, entre otros. Su iniciativa se basó, como él mismo lo dijo, en su experiencia de más de veinte años como misionero, y en las falencias que había podido detectar durante ese tiempo en la conversión de los infieles. Los débiles logros en la evangelización del septentrión mexicano se debían a las duras condiciones en las que los religiosos desempeñaban su labor, al rechazo de su persona y de sus enseñanzas por parte de los indígenas, y al difícil proceso de comunicación entre unos y otros. Se trataba de un número grande de tribus y poblados, que hablaban lenguas de mayor restricción geográfica y, dentro de ellas, con muchas diferencias dialectales. Había pasado mucho tiempo desde ese primer siglo colonial definido por lo que Ricard llamó la conquista espiritual ${ }^{3}$, cuando desbordaba el fervor vocacional de las distintas órdenes mendicantes respaldadas por la monarquía y que se dedicaron a la conversión de los infieles. A pesar de que a fines del siglo XVIII en el centro del virreinato la labor misional estaba mucho más consolidada, en los extremos fronterizos la situación no era la misma. El entusiasmo que había caracterizado a las primeras generaciones había ido perdiendo su ímpetu. Entre las causas estaban el debilitamiento vocacional y la falta de candidatos dispuestos a vivir en situaciones riesgosas y llenas de penurias. Un gran número de religiosos prefería permanecer en las principales ciudades y villas y sus alrededores, y los que adoptaban la vida misional eran los menos. Pero las misiones jugaban un papel muy importante en el control de las fronteras del norte del virreinato, de ahí la importancia que Pimentel les reconocía.

Era ese el ambiente propicio para el desarrollo de métodos alternativos de conversión permanente y de congregación de los pueblos, que se cruzarían con la nueva ideología en materia educativa que estaba invadiendo el país. El proyecto que propuso el fraile se centraba en el establecimiento de un centro dónde educar a los niños provenientes principalmente de las misiones cristianas de

3. Ricard, Robert, The Spiritual Conquest of Mexico. An Essay on the Apostolate and the Evangelizing Methods of the Mendicant Orders in New Spain: 1523-1572. Berkeley, Univ. of California Press, 1966. 
indios amigos, ya que sería mucho más fácil lograr su traslado hasta el punto donde se estableciera el Colegio. Allí habrían de recibir una educación muy completa, y después de un lapso de tiempo pre-establecido, los jóvenes saldrían ya preparados, a hacerse cargo de las misiones de sus propias naciones. Para ello, era fundamental insistir en el conocimiento de las lenguas autóctonas, pues en ellas habrían de llevar a cabo sus ministerios los nuevos misioneros una vez de vuelta a su región de origen.

\section{El proyecto}

El Padre Mariano López y Pimentel nació en Sanlúcar de Barrameda hacia mediados del siglo XVIII, y más tarde ingresó a la rama franciscana de los descalzos de la más estrecha observancia de la Provincia de San Diego de México, también llamados dieguinos ${ }^{4}$. Después de dedicar largos años a las labores propias del misionero, especialmente en reales de minas del norte mexicano, hacia fines de siglo y primeros años del XIX, se abocó a elaborar un proyecto para el establecimiento de un colegio de misiones o seminario de lenguas, como también lo llamó. La idea central de su proyecto era reunir ahí a niños provenientes de las Provincias Internas de la Nueva España, esa amplia región comprendida por Nuevo México, Texas y California, y en el norte de México las provincias de Sonora, Sinaloa, Nayarit, Nuevo León, Coahuila, Chihuahua y Durango, éstas últimas la Nueva Vizcaya ${ }^{5}$. Junto con ellos, esperaba poder recibir en su institución a niños que llegasen desde China y otras partes de Asia.

El interés de incluir la presencia de los jóvenes de oriente en el proyecto se produjo gracias al tiempo que pasó en la Nueva España un religioso francés, y que durante los cuatro o cinco años que duró su estadía pudo establecer un nexo sólido con algunas órdenes religiosas. En ese tiempo se encargó de informarlos sobre la situación que vivían en China, Corea y otras partes, los misioneros y los neófitos recién convertidos al cristianismo a fines del siglo XVIII, época marcada por serias persecuciones religiosas. El propósito del sacerdote francés era el de solicitar ayuda de la elite local y del clero mexicano para fortalecer la situación de las misiones en esos lugares, y también en Filipinas, Macao,

4. Calculando por los registros de religiosos en los conventos dieguinos de México, el Padre Mariano López y Pimentel nació alrededor de 1757 y se le pierde la pista en 1813. Datos proporcionados por Marcela Corvera Poiré, en su tesis de doctorado en Historia de la Universidad Complutense de Madrid, del año 1995: "Estudio histórico de la familia de franciscanos descalzos de la Provincia de San Diego de México, s. XVI-XX".

5. Provincias que habían pasado a formar las doce intendencias en que se dividió el virreinato, sistema instaurado por el Visitador José de Gálvez a partir de 1770. En Luis Navarro García, "Los intendentes de las Provincias Internas de la Nueva España", Temas Americanistas 19 (2007), p. 51. 
Vietnam y Tailandia, entre otros ${ }^{6}$. Para los fines de este trabajo, hemos decidido enfocar solamente la situación en la Nueva España y haremos mención, solamente cuando así se justifique, de los niños que llegarían de China, aspectos que he analizado con mayor detalle en otro trabajo?

El Padre López Pimentel identificó tres elementos responsables de que las conversiones y la evangelización en las zonas marginales del Imperio, tan alejadas entre sí y tan disímiles, no prosperaran. En su opinión, éstas fueron la escasez de misioneros y su desconocimiento de las lenguas autóctonas, y por ultimo la fuerza de la idolatría. Al analizar estos tres aspectos dentro del contexto de la época, veremos que la apreciación del religioso no distaba tanto de la situación real.

Al escribir las varias versiones de su proyecto ${ }^{8}$, lo hizo con la intención de recibir de parte de las autoridades coloniales y de la monarquía las licencias necesarias para empezar con su edificación y funcionamiento. Estuvo pendiente de planificar hasta el más mínimo detalle, e incluso solicitó a Don Manuel Tolsá, un conocido arquitecto de la época, con gusto por lo neoclásico, que elaborara los planos del futuro Colegio o Seminario de Misiones. Para buscar solución al aspecto más apremiante de su proyecto, el del financiamiento, se acercó a los ricos hacendados y mineros que formaban parte de la elite colonial quienes le prometieron su ayuda, y esperaba recibirla también de legados testamentarios y donaciones, así como de otras fuentes. El compromiso de estos grupos era evidencia de lo atractivo que el proyecto podía lucir más allá del ambiente religioso. Era la intención del fraile no ocasionarle gastos a la Real Hacienda, pues le causaban preocupación las enormes cantidades que se gastaban constantemente y desde hacía ya más de dos siglos, en el envío de misioneros desde España y el sustento de misiones y presidios. Estaba muy conciente de estar presentando su proyecto a las autoridades en momentos delicados, en vista de los enormes gastos ocasionados por las guerras recientes contra Francia e Inglaterra, sin adivinar siquiera la futura invasión de la península por las tropas de Napoleón y sus consecuencias posteriores. Por eso mismo era importante asegurar la ayuda pecuniaria y material de la comunidad, que también se vería beneficiada por la eventual pacificación de la región.

6. Letondal, Claudio Francisco, Relación de las tribulaciones de los fieles y de las necesidades del sagrado ministerio para conservar la semilla de la Fe y propagarla en las partes orientales de la Asia. México, Imprenta de Don Mariano Zúñiga y Ontiveros, 1804, p. 24: el Padre Letondal proponía el establecimiento de un colegio de misiones en algún lugar del imperio español y fuera de China, donde las persecuciones contra los cristianos los obligaban a permanecer escondidos y en constante peligro: "Sería utilísimo un grande Colegio en algunas colonias católicas, gobernado por los misioneros".

7. Para civilizar al bárbaro: Colegio de misiones en el virreinato novohispano tardío. Santiago. Publicaciones del Archivo Franciscano 97 (2007).

8. La mayoría de éstas se encuentran en el Archivo General de Indias, Sevilla. La que consulté forma parte del Archivo Franciscano de Santiago de Chile: "La paz verdadera entre Dios y los gentiles de la Asia, y América", de 1807. 
El proyecto giraba en torno a la posibilidad de albergar en un espacio propio de amplias dimensiones a un número muy grande de alumnos, alrededor de cuatrocientos niños, además de sus maestros y de los religiosos a cargo de la educación y la administración del colegio. La idea era que de cada tribu americana y de cada nación asiática, llegaría un grupo de unos doce niños, de entre ocho y diez años de edad, acompañados de sus maestros de la lengua, la cual no debían descuidar ni olvidar. Sería imperativo conservar el hábito de hablarla, al tiempo de dedicarse al estudio de toda una gama de otras materias. La propuesta del religioso se basaba en que los niños debían recibir una educación esmerada para insertarse luego de un tiempo determinado, de nuevo en sus naciones de origen. Debían aprender, además del castellano, el Evangelio y el latín, todo tipo de artes y ciencias. Los que mostraran aptitudes para el sacerdocio tomarían el hábito, al tiempo que otros se dedicarían a las actividades misionales como legos, y otros tantos fungirían de maestros de artes y oficios.

El propósito de lo anterior era dar solución, por un lado, a la escasez de misioneros, y de sacerdotes indígenas, hecho ya comprobado durante el siglo $\mathrm{XVIII}{ }^{9}$. Por el otro, al desconocimiento de las lenguas de los territorios todavía faltos de tornar a la usanza propia del castellano, donde aún quedaba mucho campo para ejercer las labores de conversión y civilización de los pueblos. Pero como el concepto de civilizar había ido evolucionando en el tiempo, de acuerdo con los preceptos ilustrados en boga, un tercer propósito sería formar hombres útiles a la sociedad y asegurar dentro de lo posible su aporte a aquellas actividades más productivas. De esa forma se alejaban del estigma con que se asociaba a los bárbaros desde tiempos aristotélicos, como sinónimo de inferior, "del que no habla griego". Los bárbaros fueron desde entonces aquellos que vivían en los confines de las fronteras, como hicieron los mongoles frente a los diferentes imperios chinos, y como sucedió con las distintas tribus germanas ad portas del imperio romano. Entre las características que distinguían al hombre de las bestias en tiempos de la Antigüedad estaba la habilidad de usar el lenguaje y la habilidad de formar sociedades civiles ${ }^{10}$. De esa forma se fueron traspasando los requerimientos básicos de lo que constituía el ser civilizado.

Para el lugar físico dónde establecer el Colegio de Misiones se exigían ciertos requisitos: la relativa cercanía o distancia con la comunidad, la amplitud de sus espacios, el abastecimiento de víveres, entre otros. Esperando que el monarca español y las autoridades hispanocoloniales le asignaran el mejor de los sitios, el Padre López Pimentel sugirió algunas alternativas de las que ya estaba

9. A mediados del siglo XVIII en el centro de la nueva España había tan solo 50 sacerdotes indígenas, según lo señala Serge Gruzinski en La colonización de lo imaginario. Sociedades indígenas y occidentalización en el México español, siglo XVI-XVIII. México, Fondo de Cultura Económica 1991, p. 261: “... esos sacerdotes indios (en general caciques) reciben de manera exclusiva parroquia indígena en que se puede sacar provecho de su dominio de la lengua local".

10. Pagden, Anthony, The American Indian and the Origins of Comparative Ethnology. Cambridge, Cambridge University Press, c1982, 1990, p. 16-20. 
al tanto, fijándose en que primara el espacio, el resguardo de las influencias nocivas de la sociedad y de las mujeres, y la posibilidad de ejercer una autosuficiencia en cuanto a la alimentación y al vestido. A la cabeza de su lista de sugerencias estaba el Castillo de Chapultepec en la ciudad de México, que se encontraba por esos tiempos desocupado, el antiguo colegio jesuita del Espíritu Santo en la ciudad de Puebla, y algún sitio en los alrededores de la villa de Aguascalientes, lugar que había sido hogar del Padre Pimentel durante muchos años, y base de su circuito misional.

Las utilidades que podría ofrecer un proyecto de esta naturaleza serían de tipo tanto temporal como espiritual. Por el lado espiritual, la conversión de poblaciones muy numerosas iba a ser ciertamente una ganancia, tanto para la Iglesia como para la Corona española. Por el lado temporal, el empuje en el campo de la educación calzaba casi a la perfección con los objetivos de la época, en que se hacían grandes esfuerzos por ilustrar al pueblo. La conjunción de ambos propósitos tendría como resultado la consolidación de una gran parte del territorio del virreinato, así como ayudar al proceso de su pacificación, y que abriría caminos para el asentamiento de poblaciones, el establecimiento y defensa de centros mineros, y el comercio. En algunos puntos de las Provincias Internas ya se habían llevado a cabo intentos por establecer poblaciones civiles, pero la mayoría con poco éxito"1.

El establecimiento de misiones y de presidios era considerado de vital importancia por la seguridad que ofrecían en la región, como se puede apreciar en este informe del presidente de las misiones en la Provincia de Sonora, Fr. Francisco Mollano, y que fechó el 18 de mayo de 1803 en la Misión de San Antonio de Oquitoa.

"Están expuestas las Misiones por el rumbo de Oriente y Norte, a insultos de los Indios Bárbaros; no tanto estas que caen al Poniente, como las que caen de Norte á Sur, a saber: San Xavier del Bac, Tumacacori, Cocospera y San Ignacio, porque en estas son frecuentes los robos que hacen los enemigos del Ganado y Caballada, y su furor suele causar otras desgracias como la del Indio de San Xavier, que ahora poco mataron en el Cerro de Santa Catalina, y á sus dos compañeros les llebaron sus bestias y trastos. Por junio de 801, dieron en Tumacacori y mataron tres cabreros, y a mas de 1360 cabezas de ganado lanar. Podría ganarse mayor seguridad si se abanzare una fundación en el antiguo Pueblo de Sonoita que es entrada frecuente del enemigo, la qual serviría de resguardo a dichas Misiones, al presidio de Santa Cruz, y por consiguiente a las demás Poblaciones del Poniente, reforzando dicha fundación con suficiente Escolta"12.

11. Osante, Patricia, "Estrategia colonizadora en el Nuevo Santander, siglo XVIII". Estudios de Historia Novohispana 30 (enero-junio 2004), pp. 17-44.

12. Archivo General de Indias, Sevilla (en adelante, A.G.I.), Audiencia de México, Legajo 2736, Provincia de Sonora, 18 de mayo de 1803, p. 3. 
Quedaba un solo aspecto por sortear, que mientras las autoridades coloniales civiles y religiosas, siguiendo la iniciativa de los ministros reales y de sus planes de educación de la juventud, se concentraban en la total substitución de las lenguas autóctonas por el castellano, con el fin de ejercer un mejor control centralizado de los dominios de España en ultramar, el Padre Pimentel insistía ferozmente en que las lenguas nativas de los gentiles se debían mantener a toda costa, pues estaba convencido de que era la única forma de lograr el trasvase religioso-cultural deseado.

Los cursos que se debían impartir en el Colegio daban primacía a la enseñanza del Evangelio y la doctrina cristiana, así como las vidas de los Padres de la Iglesia. Sería obligatoria la enseñanza de la lengua castellana, el latín, la gramática y otras artes liberales y mecánicas, así como música y dibujo. Había que empezar por enseñar las primeras letras, a leer, escribir y contar. Como parte de la importancia asignada a la conservación de las lenguas vernáculas de los distintos pueblos y naciones que participaron en el proyecto, se exigiría que de cada uno de ellos viajaran acompañando a los niños uno o dos maestros de lenguas. En la distribución interna del colegio, habría un espacio designado para la enseñanza de las artes liberales y mecánicas, así como para el desempeño de distintos oficios. En ellos debían compartir los niños de distintas naciones, para aprender unos de otros. Por ejemplo, de los niños de China, los americanos podrían aprender su civilidad además de otras técnicas en las que los orientales demostraran cierta maestría como por ejemplo la sericultura.

El Padre Pimentel consideraba que los chinos se encontraban en una escala superior de desarrollo a la de los bárbaros, ya que desde tiempos muy remotos los primeros vivían congregados en ciudades al igual que los europeos, con leyes y gobernantes que las hacían cumplir, éstas eran algunas de las características que se requerían para vivir en policía. Incluso reconoció la necesidad de que aprendieran ciertas ciencias mayores como la astronomía y las matemáticas, para lograr acercarse a sus gobernantes por medio del conocimiento. En este aspecto el interés del fraile recuerda la participación de ciertas órdenes religiosas en la corte de algunos emperadores chinos.

A los segundos, a pesar de usar siempre un tono paternalista, los describió como de una naturaleza nómada, sin asentamientos fijos, vagando por los montes y los cerros como las bestias, en busca de abrigo y alimento. La descripción debió ser certera ya que no se distanció mucho de la opinión del ingeniero militar Juan de Pagazaurtundúa al referirse a la Provincia de la Nueva Vizcaya de 1797:

"El terror que aquellos Yndios salvages, Ilamados Apaches, (cuio número de naciones aún esta por averiguarse) há infundido justamente en aquellos vecinos con sus continuos, é inhumanos destrozos en sus vidas, y haciendas, es causa de que no vea el mundo los immensos tesoros que están sepultados en aquellos Montes: Estos Barbaros son Yndios errantes, abitan las cañadas, o intermedios entre montes y montes: no profesan Religión alguna... sus principales armas son arco, flecha, y lanza, y muchos fusil: á caba- 
Ilo son diestrisimos, y mui agiles a pie. Si no fuera por la persecucion incesante de aquellas valerosas tropas, hubieran ya acabado con las haciendas, y gentes de aquellos terrenos, y estarian mucho mas próximos de Mexico"13.

Lograr congregarlos a vivir en comunidades estables donde podrían ser convocados por el son de la campana sería ya un gran paso. Desde sus orígenes, la categoría de bárbaro había tenido una connotación cultural más que racial, lo que facilitó su traslado como concepto al mundo cristiano, donde se le confundió con el no-cristiano, pasando en poco tiempo a ser prácticamente sinónimo de pagano. El otro lado de la moneda era su asociación con los que se comportaban de forma salvaje e incivilizada. Ahora correspondía a las autoridades civiles y eclesiásticas coloniales sacar a esos salvajes e incivilizados infieles de su estado e introducirlos a la corriente hispanizada. Se consideraba que el indígena vivía en una etapa temprana de desarrollo humano. Con la ayuda del europeo podría dejar atrás su estado de inmadurez y acercarse progresivamente a un estado de adulto $^{14}$. El Padre Pimentel no compartía la idea generalizada del atraso del indígena; al contrario, estaba convencido de sus habilidades al compararlos con los crioIlos, a los que llamó americanos, y con los españoles. Por ello, y convencido de su capacidad, proponía unos exigentes planes de estudio y de preparación para poder participar luego activamente en la sociedad colonial.

En cuanto a las habitaciones dentro del Colegio, éstas se encontrarían segregadas por nación o pueblo, colocando a todos los provenientes de Asía de un lado del establecimiento, y a los de las naciones americanas del otro. Dentro de esos dos grandes sectores, ciertas naciones serían vecinas de otras que de tiempo atrás consideraban sus enemigos tradicionales, como por ejemplo, los apaches de los tejas, o para las naciones asiáticas, los mongoles de los chinos. En espacios delimitados iban a tener que convivir, estudiar y aprender lo mejor que tenía cada grupo que ofrecer. El inevitable roce entre ellos era un aspecto que habría que solucionar para lograr la buena convivencia y el intercambio cultural deseado.

La finalidad era la de formar a hombres útiles para la vida civil y cristiana, instruyéndolos no solo en la religión, como catequistas o misioneros a aquellos que mostraran aptitud. Dependiendo de las habilidades personales, también recibirían la instrucción adecuada para convertirse en maestros de escuela, artistas, fabricantes o artesanos. En este aspecto el fraile sanluqueño reconocía la capacidad del indígena y el poder de la educación en efectuar los cambios necesarios para hacer de ellos vasallos útiles a la Corona.

13. Moncada Maya, Omar, "Una descripción de las Provincias Internas de la Nueva España a finales del siglo XVIII. La descripción del ingeniero militar Juan de Pagazaurtundúa". Revista Bibliográfica de Geografía y Ciencias Sociales 436, (2003). En línea: http://www.ub.es/geocrit/b3w-436.htm.

14. Pagden, The Fall of Natural Man, p. 124, 142, para una discusión sobre la condición del indígena en base a los postulados de la filosofía aristotélica y sus consecuentes interpretaciones por pensadores cristianos. 


\section{Razones del Padre López Pimentel y sus justificantes}

Entre las razones principales que expuso Pimentel para justificar su proyecto, junto con su consecuente autorización y elaboración, fueron la escasez de misioneros y el hecho de que no hablaban la lengua de los pueblos a los que iban a convertir. La otra fue la fuerza de la idolatría. Era una realidad que no se había alcanzado la conversión de la totalidad de los habitantes de las amplias regiones comprendidas por las Provincias Internas de la Nueva España, en contraste con los logros del centro del país. Y por lo tanto, a consecuencia de la debilidad de los esfuerzos y los logros misionales, había un relapso a las costumbres idolátricas que incomodaba. Entre todos los casos documentados de idolatría uno en la Provincia de Nayarit debió haber causado un gran impacto en su tiempo, pues Pedro Alonso O'Crouley lo consignó en su descripción del territorio mexicano como algo fuera de lo común. Tuvo lugar en la misión de Dolores, cercana al puerto de San Blas, cuando la misión todavía estaba en manos de la Compañía de Jesús, antes de que pasara a los franciscanos ${ }^{15}$.

También era cierto que los misioneros escaseaban. Ya la idea utópica de los primeros siglos de colonización se había gastado. El atractivo para los religiosos en sus conventos españoles de trasladarse a las Colonias había perdido fuerza, y llegaban los nuevos misioneros desde España solo gracias a las solicitudes recurrentes de los superiores ${ }^{16}$. Por otro lado, los peligros e incomodidades en los territorios francamente despoblados, aún con la seguridad que ofrecían los presidios y los soldados que acompañaban a los misioneros en sus jornadas, animaban a pocos. El funcionamiento de las misiones en el norte de México había quedado prácticamente en manos de los Colegios Apostólicos de Propaganda Fide de la Orden Franciscana. De sus centros salían los misioneros a lugares lejanos e inhóspitos, y en gran parte gracias a ellos se mantuvo el equilibrio entre la barbarie y la civilización.

En su informe al Gobernador Intendente de Sonora, -y que fue a su vez remitido al Comandante General de las Provincias Internas, Don Pedro de Nava-, Fray Juan Phelipe Martínez hizo relación de su reciente visita a las misiones. Fray Martínez era presidente de las misiones de la Baja Pimería en Sonora, que antiguamente habían estado en manos de los jesuitas, y en ese momento bajo el control del Colegio de Jalisco. En su informe, el fraile constató el deplorable estado de casi todas las iglesias y de las casas de los misioneros. Se refirió a la pobreza tanto de la misión como del ministro a cargo y de los indígenas que en ella habitaban, además de su reducido número.

15. Malvido Miranda, Elsa, "La guerra contra las momias en la Nueva España. El siglo XVIII, jesuitas, franciscanos, autoridades seculares e inquisición". Chungará (Arica) 32-2 (julio 2000), pp. 199-205. Por el puerto de San Blas, importante en esa época, pensaba el Padre Pimentel hacer llegar a los niños desde China, por medio del trayecto entre Filipinas y la costa noroeste de México.

16. Brading. D. A., Church and State in Bourbon Mexico. The Diocese of Michoacán, 1749 1810. Cambridge University Press, 2002, p. 80. 
"Mochopa. Solo en la denominación es Pueblo, pues lo hallé derrocado y casi desierto, y solo se vieron en el entre hombres, mugeres y niños ocho almas, y lo demás de su gente (que es muy poca) según me informaron, todos andan por los montes y poblaciones buscando con que mantenerse, pues es suma su miseria, y casi ningunas tierras de labor. De todo lo qual resultan gravísimos inconvenientes, viéndose su Iglesia desierta y derrocada, las pocas Sagradas Imágenes sin culto, los ornamentos y vasos sagrados en mal estado, y expuestos a la profanación y ruina de los Enemigos Apaches" ${ }^{\prime 17}$.

En varias ocasiones durante el informe de su visita, el Presidente de las misiones de la Baja Pimería se refirió a lo inhóspito de la tierra que quedaba bajo su responsabilidad como "estas infelices Provincias", y se lamentaba de la pobreza que rodeaba el trabajo de los frailes en los pueblos de indios. También hizo varias referencias a las incursiones de algunas tribus bárbaras, especialmente de apaches y de los "casi irreductibles indios seris", a las tierras de las misiones, con el fin de robar el ganado y destruir las cosechas. Consideraba apremiante la ayuda del gobierno, para mejorar la situación de las misiones y de los misioneros. Con su fortalecimiento y con el establecimiento de más de ellas podrían ofrecer una mejor barrera de protección contra los ataques y reducir el número de hogares que quedaban en abandono, perdiendo sus habitantes la oportunidad de una educación cristiana y civil. Muchos de los que abandonaban los pueblos de indios se contrataban en otros lugares como sirvientes y otros andaban con "mugeres hurtadas $^{\prime 18}$. Difícilmente podrían lograrse los objetivos imperiales de pacificar el territorio y fortalecer las fronteras contra las incursiones de extranjeros si el cordón de misiones y presidios se encontraba en esas condiciones.

Por otro lado, para fines del siglo XVIII, el centro de México se encontraba prácticamente unificado en cuanto a la lengua. Desde poco después de la Conquista, y aprovechando la unificación lingüística que imperaba entonces gracias a la extensión del control ejercido por las redes imperiales y comerciales de los aztecas, las distintas órdenes mendicantes se habían dedicado a aprender las lenguas de mayor difusión, el náhuatl, el otomí y el tarasco entre las principales, y a escribir en ellas gran cantidad de obras, gramáticas y diccionarios, catecismos, sermones y manuales para misioneros ${ }^{19}$. Pero dos siglos después, en los márgenes del virreinato, la situación era algo diferente. Los poblados que quedaban sin convertir tenían una lengua de uso restringido y difícil de aprender, por lo que los misioneros no valoraban su aprendizaje. Era preferible que los indígenas aprendieran el castellano. Sin embargo, al fraile dieguino le seguía

17. A.G.I., México 2736, Provincia de Sonora, 9 julio 1803, pp. 12.

18. A.G.I., Provincia de Sonora, 9 julio 1803, pp. 14-18.

19. Este tema ha sido ampliamente explicado por la historiografía, en especial por Robert Ricard y Christian Duveger, La conversión de los indios de Nueva España. México, Fondo de Cultura Económica, c1987, c1996, y por Rodríguez González, Jaime, "Los franciscanos y la cultura en México". Archivo Ibero-Americano 241-242 (2002), pp. 1-224. 
preocupando, como había sucedido con tantos otros, la dificultad para poder asimilar los conceptos abstractos propios de la religión si no se manejaba la lengua, ni siquiera a un nivel elemental.

Todo eso conducía a un ambiente propicio en el que la escasa presencia del misionero y el aprendizaje superficial de las enseñanzas del catecismo y de la doctrina cristiana dejaban el camino abierto a un relapso a las costumbres idolátricas de antaño, muchas de las cuales nunca se habían abandonado. Además, la constante opresión a la que se veían sujetos los indígenas por parte de los españoles, civiles, militares o religiosos, ayudaba a la deserción y abandono de las misiones y de las enseñanzas tanto de carácter útil como religioso.

Uno de los objetivos prácticos del gobierno ilustrado en las colonias hispanoamericanas, y que trabajaba en pos del bien común de la nación, fue la unificación del idioma, que se hablara solo el castellano. Para ello las autoridades eclesiásticas pidieron a los misioneros y párrocos que no se hablara en otra lengua que esa a los fieles. Se juzgó necesario evitar el uso de las lenguas bárbaras para poder explicar con fundamento los principales preceptos de la religión. Sin embargo, los indígenas no siempre aceptaron de buena gana esta obligación, y las muestras de resistencia aumentaban a medida que se incrementaba la distancia de los focos administrativos, donde el control era menor ${ }^{20}$.

\section{Ambiente ilustrado}

Eran tiempos en que la corriente ilustrada ejercía su influencia y permeaba el ambiente, sobre todo en lo que a educación se refería, con un telón de fondo que hablaba del progreso social y científico. Circulaba material impreso sobre nuevos métodos y técnicas de instrucción. Las publicaciones y las gacetas semanales hablaban constantemente de certámenes educativos, de inauguraciones de colegios para niñas y para niños, de órdenes religiosas llegadas de Europa con el único fin de educar a la juventud, fuera ésta española, criolla o mestiza. Aunque Pimentel aseguró en sus escritos haber revisado las obras de varios filósofos e ilustrados, y no haber encontrado una que se ajustara a sus propósitos, desafortunadamente no los mencionó de nombre. Solo dejó constancia de haber revisado con regular frecuencia la Gazeta de México, publicación semanal que, además de aportar información sobre distintos sucesos políticos en la península y en sus países vecinos, se fue especializando en entregar noticias sobre los certámenes de escuelas municipales de toda la Nueva España, a diferencia del Diario de México, que más bien publicaba artículos sobre los avances pedagógicos en Europa ${ }^{21}$.

20. Tanck de Estrada, Dorothy, Pueblos de indios y educación en el México colonial, 17501821. México, El Colegio de México, p. 339.

21. Tanck de Estrada, Dorothy, La educación ilustrada, 1786-1836. México, El Colegio de México, 2005, p.166. 
El debate sobre la humanidad del indígena que se desarrolló a raíz del descubrimiento del nuevo mundo había ido perdiendo fuerza en el siglo XVIII ante el enfrentamiento ideológico de los contrastes entre el europeo y el americano y el aumento en las distancias entre las distintas clases sociales ${ }^{22}$. La preocupación por el bienestar del indígena en una zona de frontera obedecía a la preocupación de hacer de él -del bárbaro- un hombre civilizado acorde con las expectativas del discurso ilustrado de fines de siglo. En el espacio de contacto entre dos territorios se esperaba que las ideas y las costumbres fueran adoptadas por los menos avenidos, imitando aquellos rasgos sociales y culturales que distinguían al hombre de la bestia. Entre ellos, la adopción de un patrón urbano de asentamiento, para congregarse en villas y poblados, la vestimenta, el comportamiento, eran signos de civilidad. Uno de los aspectos principales cómo se proponía lograr esta asimilación era por medio de la educación, tema de avanzada, con los esfuerzos de los funcionarios coloniales que siguieron la iniciativa del Ministro Melchor Gaspar de Jovellanos en la metrópoli, por hacerla asequible a todos y de forma gratuita ${ }^{23}$. En la Nueva España el empeño que empezó en las ciudades y centros urbanos de mayor densidad, se fue extendiendo hacia el norte, hacia localidades más distantes y de menor tamaño y hacia las zonas rurales ${ }^{24}$.

Como resultado de los programas de castellanización de la monarquía expresados en varias cédulas reales del último tercio del siglo XVIII, en el virreinato novohispano los maestros de escuela de primeras letras fueron reemplazando poco a poco las escuelas de doctrina cristiana. Con las cédulas reales de la década de los setenta se había establecido el uso del castellano entre los indígenas así como la creación de escuelas, a diferencia de lo que había sucedido durante todo el periodo colonial, en que su educación había estado prácticamente en manos de los religiosos y restringida a la enseñanza del catecismo y de ciertas prácticas artesanales ${ }^{25}$.

\section{De la utilidad a la felicidad}

Uno de los rasgos característicos de las corrientes ilustradas que llegaron de la metrópoli a las colonias como consecuencia de las reformas administrativas del gobierno borbónico fue la noción de felicidad. Este estado se podía obtener en relación proporcional a la utilidad que el hombre brindara a la sociedad, en

22. Roig, Arturo Andrés, "Momentos y corrientes del pensamiento humanista durante la época de la colonia hispanoamericana: Renacimiento, barroco e ilustración". Revista de Filosofía (Universidad de Chile) XXI-XXII (diciembre 1983), p. 71-72.

23. Gaspar de Jovellanos, Melchor, "Memoria sobre educación pública". Obras Escogidas II. Madrid, Espasa-Calpe, S.A., 1935, pp. 51-174.

24. Tanck de Estrada, Dorothy, "The Escuelas Pías of México City, 1786-1820". The Americas XXXI-1 (July 1974), p. 67.

25. Tanck de Estrada, Dorothy, La educación ilustrada, p. 185, las cédulas de 1770, 1772, 1774 y 1778. 
búsqueda siempre del bien común. Entonces, el poder educar a seres útiles era del más alto reconocimiento.

Uno de los caminos para lograr la felicidad en los aspectos terrenales era el del crecimiento productivo y de la abundancia, en la agricultura, en las industrias domésticas, fomentando una educación basada en los conocimientos prácticos, especialmente de las ciencias útiles. Era importante tomar en cuenta la dimensión espiritual del hombre, al hablar de felicidad, Pero el concepto tenía también un aspecto económico que buscaba proveer a los individuos de bienestar y de comodidad. El camino para lograrlos empezaba con el ofrecimiento de una educación a todos, acrecentada con conocimientos prácticos. Por ello, para que todos pudieran tener acceso a ella, era imperante que fuera popular y gratuita ${ }^{26}$.

Aunque este discurso en sus orígenes estaba orientado a la juventud española, el proyecto del Padre Pimentel para instruir al indígena cabía dentro de esta filosofía pues uno de sus propósitos fundamentales era evitar el ocio y el vagabundaje otorgando conocimiento útil. Al insertar en su plan de estudios el conocimiento de las artes liberales y mecánicas y otros cursos a la vanguardia en los planes educativos, el fraile se aseguraba de la aceptación de su proyecto por parte de las autoridades civiles a la cabeza del gobierno, de manera que se adelantaba a cualquier objeción que le pudieran hacer.

En el ambiente descrito por el comerciante Pedro Alonso O'Crouley, y avalado por informes de militares y misioneros, la frontera era la que separaba la civilización de la barbarie. Las fronteras, compuestas a veces por una serie de líneas imaginarias, otras veces por hitos geográficos, eran las que separaban, las que distinguían una región de otra, las que demarcaron dos espacios distintos, donde además se cruzaron las fronteras socioculturales, fronteras construidas por las diferencias de cada pueblo, de su lengua e ideología, de sus creencias, tradiciones y costumbres, de su expresión externa en el traje, el adorno, la vivienda. A pesar de la porosidad de la frontera, un lado estaba ocupado por la sociedad colonial compuesta por españoles, criollos, mestizos, indígenas y las distintas castas. El otro, por las tribus descritas como de salvajes hostiles e infieles.

Fueron estas "fronteras" socioculturales las que mantuvieron al habitante de las Provincias Internas al margen de los nuevos patrones de ascenso social y de incorporación a la sociedad colonial que se habían ido dando. Con fines muy específicos, los representantes imperiales portadores de la filosofía ilustrada levantaron esfuerzos por zanjear esa frontera entre dos mundos distintos, en lo geográfico, y en lo social y cultural. Participaron en esos esfuerzos las misiones y los presidios, los religiosos y la milicia, los colonos y los mineros, y los funcionarios de distintos rangos en representación de las autoridades.

26. Martí, Marc, "La idea de felicidad en el pensamiento de Jovellanos". Brocar, Cuadernos de Investigación Histórica 25 (2001), p. 142. 
Pero también participaron a su manera individuos como Pimentel, que por medio de su empuje creativo ofrecía soluciones para problemas mucho más allá de su competencia. Las situaciones difíciles a las que se vio enfrentada la monarquía española con la invasión francesa de la península a fines de la primera década del siglo XIX postergó la posibilidad de obtener las autorizaciones reales y de ver realizado el proyecto propuesto por el fraile, y los movimientos independentistas en las colonias irrumpieron en el tejido colonial de manera que las bases económicas sobre las que se recargaba el futuro del proyecto se vieron seriamente dañadas. A pesar de eso, el fraile siguió persiguiendo sus objetivos durante varios años más, encontrándose siempre con objeciones similares, el gran gasto que su proyecto iba a representar a la Real Hacienda en tiempos difíciles para todos. No hay indicios de la realización del proyecto del Padre López Pimentel, lo que no le resta validez a su autentica preocupación por ofrecer soluciones a los problemas que detenían el avance tanto espiritual como temporal de los habitantes de la extensa frontera norte del virreinato, misma preocupación que fue compartida en otras esferas del quehacer colonial. Los informes de militares y misioneros así como los escritos de viajeros y funcionarios que por un lado ayudaron a consignar la figura del bárbaro en el imaginario colectivo, abrieron el camino para iniciar los cambios ya largamente anunciados.

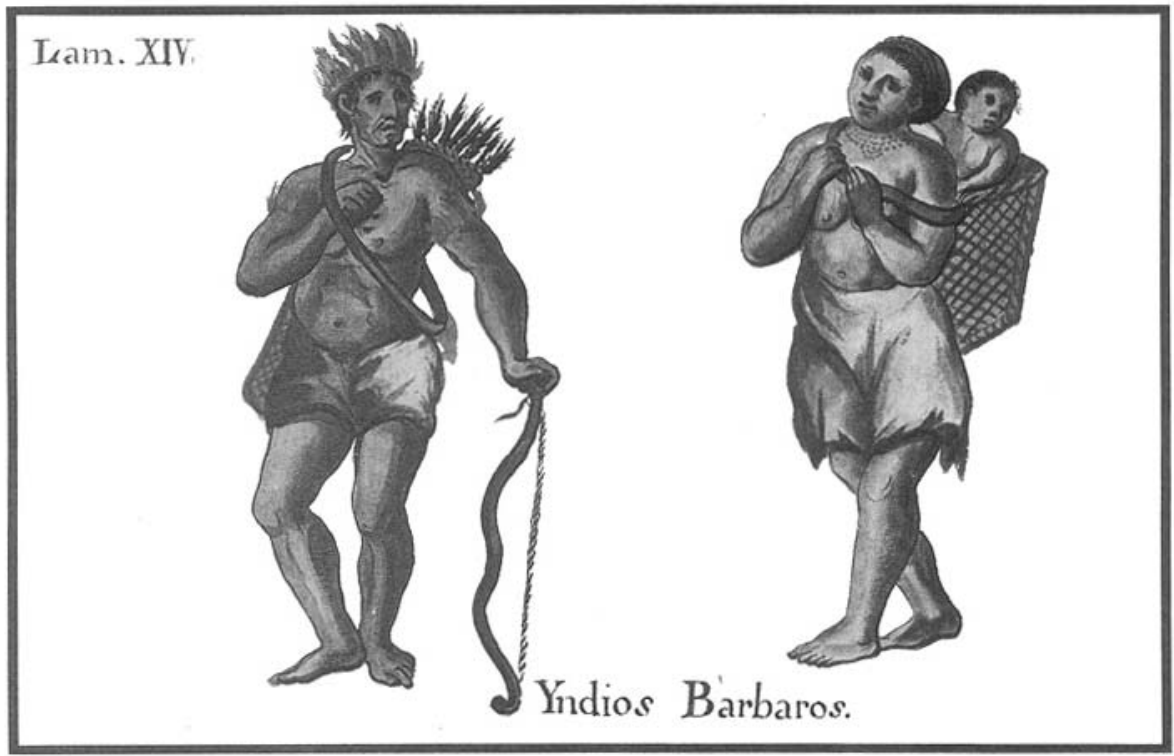

Imagen 1. Indios bárbaros. 
LA FRONTERA QUE NOS UNE: PROYECTO PARA EDUCAR AL BÁRBARO, MÉXICO, 1807

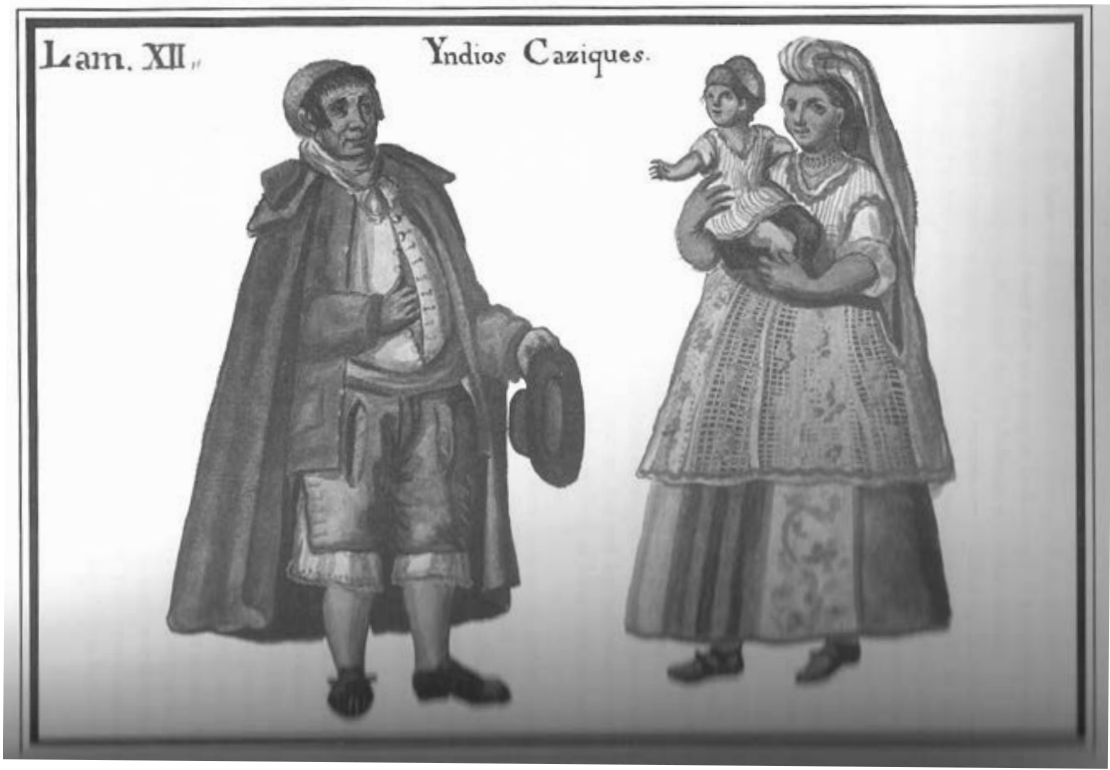

Imagen 2. Indios caciques.

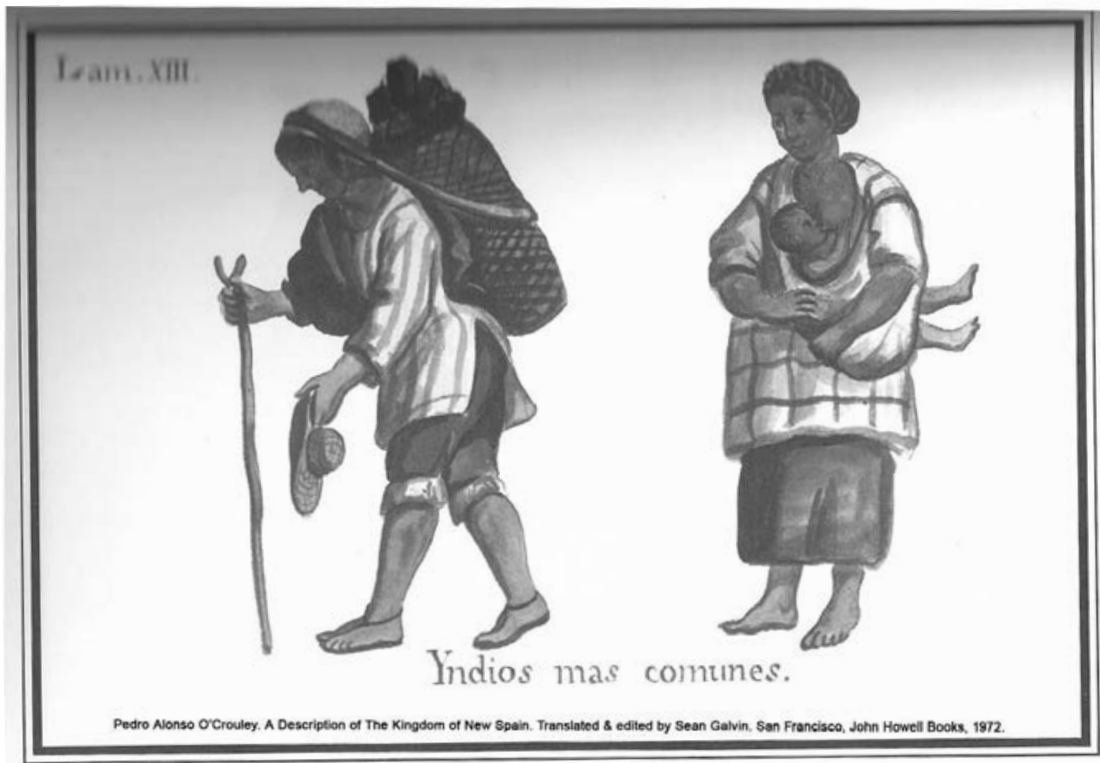

Imagen 3. Indios más comunes. 


\section{Bibliografía}

ARCHIVOS

Archivo General de Indias, Sevilla. IMPRESOS

BOCCARA, Guillaume. "Rethinking the Margins/Thinking from the Margins: Culture, Power, and Place on the Frontiers of the New World". Identities: Global Studies in Culture and Power 10 (2003), pp. 59-81.

BRADING, D. A. Church and State in Bourbon Mexico. The Diocese of Michoacán, 1749-1810. Cambridge, Cambridge University Press, 2002.

CORVERA POIRE, Marcela. "Estudio histórico de la familia de franciscanos descalzos en la provincia de San Diego de México, s. XVI-XX". Tesis para optar al grado de doctorado en Historia, Universidad Complutense de Madrid, 1995.

ESPINOSA, Isidro Félix de. (1746) Crónica de los Colegios Apostólicos de Propaganda Fide en la Nueva España. Luis Gómez Canedo, ed., Washington, Academy of American Franciscan History, 1964.

GRUZINSKI, Serge. La colonización de lo imaginario. Sociedades indígenas y occidentalización en el México español, siglos XVI-XVIII. México, Fondo de Cultura Económica, c1988, 1991.

HILlOCK, Laura. Para Civilizar al Bárbaro. Un Colegio de Misiones en el Virreinato Novohispano Tardío. Santiago. Publicaciones del Archivo Franciscano 97 (2007).

JOVELLANOS, Melchor Gaspar. "Memoria sobre educación pública". Obras Escogidas II. Madrid, Espasa-Calpe, 1935, pp. 51-174.

LETONDAL, Claudio Francisco. Relación de las tribulaciones de los fieles y de las necesidades del sagrado ministerio para conservar la semilla de la Fe y propagarla en las partes orientales de la Asia. Dedicada a la gloriosísima patrona universal de la América Septentrional la Santísima Virgen de Guadalupe, Nuestra Señora. México, Imprenta de Don Mariano de Zúñiga y Ontiveros, 1804.

MALVIDO MIRANDA, Elsa. "La guerra contra las momias en la Nueva España. El siglo XVIII, jesuitas, franciscanos, autoridades seculares e inquisición". Chungará (Arica) 32-2 (julio 2000), pp. 199-205.

MÁRQUEZ CARRILLO, Jesús. "Instituciones educativas, proyecto social y comunidades científicas en Puebla, 1765-1835". Revista Mexicana de Investigación Educativa 1-2 (julio-diciembre 1996), pp. 461-478.

MARTí, Marc. "La idea de felicidad en el pensamiento de Jovellanos". Brocar: Cuadernos de Investigación histórica 25 (2001), pp. 137-148.

MONCADA MAYA, Omar. "Una descripción de las Provincias Internas de la Nueva España a finales del siglo XVIII. La descripción del ingeniero militar Juan de Pagazaurtundúa". Revista Bibliográfica de Geografía y Ciencias Sociales 436 (2003). Disponible en: http://www.ub.es/geocrit/b3w-436.htm.

NAVARRO GARCÍA, Luis. "Los intendentes de las Provincias Internas de Nueva España". Temas Americanistas 19 (2007), pp. 51-73. 
O'CROULEY, Pedro Alonso. (1774) A Description of The Kingdom of New Spain. Translated \& edited by Sean Galvin. San Francisco, John Howell Books, 1972. OSANTE, Patricia. "Estrategia colonizadora en el Nuevo Santander, siglo XVIII". Estudios de Historia Novohispana 30 (enero-junio 2004), pp. 17-44.

PAGDEN, Anthony. The Fall of Natural Man. The American Indian and the Origins of Comparative Ethnology. Cambridge, Cambridge University Press, C1982, 1990.

RICARD, Robert. The Spiritual Conquest of Mexico. An Essay on the Apostolate and the Evangelizing Methods of the Mendicant Orders in New Spain: 1523-1572. Berkeley, University of California Press, 1966.

ROIG, Arturo Andrés. "Momentos y corrientes del pensamiento humanista durante la época de la colonia hispanoamericana: Renacimiento, barroco e llustración". Revista de Filosofía (Universidad de Chile) XXI-XXII (diciembre 1983), pp. 55-83.

TANCK DE ESTRADA, Dorothy. "The Escuelas Pías of México City, 1786-1820". The Americas XXXI-1 (July 1974), pp. 51-71.

TANCK DE ESTRADA, Dorothy. Pueblos de indios y educación en el México colonial, 1750-1821. México, El Colegio de México, 1999.

- La educación ilustrada, 1786-1836: educación primaria en la Ciudad de México. 2a. ed. México, El Colegio de México, c1984, 2005.

VOLTAIRE. Candide ou l'Optimisme. Paris, Pocket, 2004.

WEBER, David. Barbaros: Spaniards and their Savages in the Age of Enlightenment. New Haven, Yale University Press, 2005. 
